\title{
NASCENTES DA SUB-BACIA HIDROGRÁFICA DO RIO POXIM, ESTADO DE SERGIPE: DA DEGRADAÇÃO À RESTAURAÇÃO ${ }^{1}$
}

\author{
Robério Anastácio Ferreira², Antenor de Oliveira Aguiar Netto², Thadeu Ismerim Silva Santos ${ }^{3}$, Bruno \\ Lima Santos ${ }^{4}$ e Eduardo Lima de Matos ${ }^{5}$
}

\begin{abstract}
RESUMO - Estudos ambientais em bacias hidrográficas são fundamentais para o entendimento do uso dos recursos naturais e dos problemas relacionados à ocupação do espaço. Em Sergipe, há necessidade de se obter informações para fins de planejamento e gestão futura de suas bacias hidrográficas, uma vez que gradualmente observa-se uma redução do volume produzido nos cursos d'água e da qualidade de suas águas, que são imprescindíveis para o abastecimento humano, a utilização na agricultura e na indústria. Devido ao acelerado processo de supressão da vegetação na sub-bacia hidrográfica do rio Poxim, formada pelos rios Poxim-mirim, Poxim-açu, e Pitanga e seus pequenos tributários, foi realizado um diagnóstico para se verificar o estado de conservação das suas principais nascentes, a situação quanto ao fluxo de água, as formas de uso e ocupação do solo no entorno destas e os tipos fisionômicos de vegetação remanescentes. As informações obtidas serão úteis para a realização de projetos de restauração ambiental, a promoção de melhorias no ambiente e nas comunidades rurais e resgate da diversidade da flora e fauna nestas áreas. Observou-se que as 20 principais nascentes dos rios e tributários que compõem a sub-bacia hidrográfica do rio Poxim, apresentam alterações decorrentes da acelerada antropização (90\%), a maioria delas (65\%) com elevada degradação (sem raio mínimo de 50m de vegetação) e ocupadas por agricultura (50\%) e pastagens (35\%). Somente duas nascentes encontram-se preservadas. Quanto à composição florística, as espécies identificadas (43) podem ser utilizadas em projetos futuros para restauração das nascentes e dos cursos d'água nesta sub-bacia hidrográfica.
\end{abstract}

Palavras-chave: Restauração Ambiental, Bacia hidrográfica e Mata ciliar.

\section{THE SUB-BASIN SPRINGS OF POXIM RIVER, STATE OF SERGIPE: THE DEGRADATION TO RESTORATION}

\begin{abstract}
Environmental studies on river basins are fundamental to understanding the natural resources use and the problems related to the space occupation. In Sergipe, it is necessary to obtain information for planning purposes and future management of their watersheds, once the watercourses volume and its quality are reducing gradually, which are essential for human supply and use in agriculture and industry. Due to the accelerated removal of vegetation in the river Poxim sub-basin, formed by the Poxim-Mirim, Poxim-Açu, Pitanga rivers, and its small tributaries, a diagnosis was carried out to verify the conservation status of their main sources, the situation on the water flow, the different uses, and land use around these sources and the remaining vegetation physiognomic types. The information is useful for carrying out environmental restoration projects, promoting improvements in the environment and in the rural communities and for the flora and fauna diversity rescue in these areas. It was observed that the 20 rivers sources top and tributaries that compose the river Poxim sub-basin showed changes from accelerated human anthropization (90\%), most (65\%) with high degradation (no vegetation in the minimum radius of $50 \mathrm{~m}$ ), being occupied by agriculture (50\%) and pastures (35\%). Only two sources were preserved. The floristic composition, the identified species (43) can be used in future projects for sources and watercourses restoration in this sub-basin.
\end{abstract}

Key words: Environmental restoration, Watershed and Riparian vegetation

\footnotetext{
${ }^{1}$ Recebido em 26.05.2008 e aceito para publicação em 16.12.2010.

${ }^{2}$ Universidade Federal de Sergipe, UFS, Brasil. E-mail: <raf@ufs.br>, antenor.ufs@gmail.com

${ }^{3}$ Consultoria e Projetos Ambientais - COPERA, Brasil. E-mail: <thadeu.copera@gmail.com>.

${ }^{4}$ Empreendimentos Florestais Ltda - EMFLORS, Brasil. E-mail: <bruno-bls@hotmail.com>.

${ }^{5}$ Universidade Federal de Sergipe, UFS, Brasil. E-mail: <elmatos@infonet.com.br>.
} 


\section{INTRODUÇÃO}

A sub-bacia hidrográfica do rio Poxim, composta pelos rios Poxim-Açu, Poxim-Mirim e Pitanga, pertence à bacia hidrográfica do rio Sergipe e é de grande importância para o abastecimento de água da capital do Estado de Sergipe, Aracaju. Nas áreas de nascentes dos cursos d'água predominam pequenas propriedades rurais nas regiões serranas; no curso médio dos rios, encontram-se grandes propriedades agrícolas produtoras de cana-de-açúcar, e em sua foz estendem-se as áreas industriais e urbanas. Apesar de sua importância social e econômica, a sub-bacia hidrográfica do rio Poxim encontra-se em alto estado de degradação ambiental, principalmente no que se refere à supressão de sua vegetação ciliar.

Diante dessa problemática, é necessário adotar medidas que visem dar suporte às ações de restauração ambiental, considerando as diversas formas de uso dos solos e as necessidades das comunidades. Deve-se entender que a restauração ecológica é atividade orientada para iniciar ou acelerar os processos de recuperação de ecossistemas, considerando-se a sua saúde, integridade e sustentabilidade (CLEWELL et al., 2002). E, ainda, de acordo com esses autores, na restauração objetiva-se retornar o ecossistema à sua condição original, ou trajetória histórica.

É necessário enfatizar que a restauração senso strictu torna-se meta quase inatingível, pois haveria a necessidade de devolver o ecossistema à sua condição original ou trajetória história (RODRIGUES e GANDOLFI, 2000). Nesse caso, segundo os referidos autores, entende-se como a necessidade de restaurar o ambiente o mais próximo possível da sua condição anterior à degradação, ou seja, restauração senso lato, que é definida como estado estável alternativo ou intermediário.

Associado ao entendimento das formas de uso e estádio de conservação, a realização de levantamentos florísticos e, ou, fitossociológicos também é imprescindível para subsidiar tais ações. Os levantamentos florísticos visam obter conhecimento prévio da composição das formações vegetacionais, fornecendo subsídios para estudos mais detalhados e dados básicos. A fitossociologia consiste no reconhecimento e definição de comunidades vegetacionais, no que se refere à origem, estrutura, classificação e relações com o meio (FELFILI e REZENDE, 2003).
Nas regiões tropicais, a exploração indiscriminada dos recursos naturais é cada vez maior. Estima-se que aproximadamente 17 milhões de hectares/ano sejam convertidos de suas formas naturais para outros usos (LAMB e GILMOUR, 2003). Isso é decorrente da importância desses recursos como alternativa econômica para fontes de renda das comunidades, que em algumas situações dependem exclusivamente deles para sobreviver

No Brasil, de acordo com levantamentos da Organização das Nações Unidades para Agricultura e Alimentação, (FAO) realizado em 2000, a cobertura florestal representava $64,5 \%$ do território, sendo distribuída em 544 milhões de hectares de florestas nativas e 5 milhões de hectares de florestas plantadas. As demais áreas foram convertidas em usos para a agricultura, pecuária e instalações de infraestrutura (PNUMA/MMA, 2002). No Estado de Sergipe, de acordo com Souza e Siqueira (2001), em face do acelerado quadro de degradação e retirada da vegetação, o percentual remanescente da área de domínio da Mata Atlântica original é inferior a 1\%. Entretanto, em estudo recente Santos (2009) retificou essa informação, mencionando que a faixa de vegetação no Estado correspondia a 8\%.

Considerando a dimensão de uma bacia hidrográfica à semelhança do rio Poxim, deve-se imaginar que a restauração ambiental envolve aspecto mais amplo do que simplesmente sítios particulares ou propriedades onde as nascentes estão situadas. Nesse contexto, a restauração da paisagem de acordo com Lamb et al. (2005) deve envolver outros aspectos, além da vegetação, nas áreas de preservação permanente. De acordo com esses autores, alguns fatores devem ser considerados para o planejamento de implantação de reflorestamentos visando à restauração da paisagem, como: realizar arranjo institucional adequado, além dos aspectos legais e de policiamento; fornecer informações e dar assistência técnica aos produtores ou às comunidades sobre as espécies empregadas nos plantios, quanto aos aspectos silviculturais e valores de mercado; e desenvolver sistemas silviculturais com manutenção mais rápida e mais moderna.

De acordo com Santos et al. (2007), em estudo realizado na bacia hidrográfica do córrego do Romão, situado no Município de Viçosa, MG, as alternativas de manejo dessa não devem levar em consideração apenas as alternativas técnicas. Segundo os citados autores, as intervenções em bacias hidrográficas devem 
também considerar os aspectos econômico, ambiental e cultural, pois tais fatores poderão interferir no grau de organização e união dos proprietários de terras e moradores, considerando-se a sustentabilidade dos recursos naturais.

Em caso de áreas de preservação permanente, considera-se que programas de restauração só podem ser bem-sucedidos se os proprietários rurais enxergarem os reflorestamentos como atrativos, proporcionando benefícios e pagamentos por bens e serviços ecológicos, como: melhoria da qualidade e aumento da quantidade de água produzida, sequestro de carbono e conservação da biodiversidade (LAMB et al., 2005).

Em algumas situações, entretanto, definir programas e ações prioritárias para restaurar paisagens baseando-se apenas nos tipos de habitats característicos ou na forma de cobertura vegetal, a partir de padrões métricos como o índice de fragmentação de determinada região ou, ainda, considerando objetivos muito amplos como a conservação da biodiversidade, podem constituir obstáculos reais para alcançar efetiva restauração desses habitats (MILLER e HOBBS, 2007).

As florestas e demais formas fisionômicas da vegetação são definidas no Código Florestal Brasileiro, concebendo-se a possibilidade de intervenções em áreas destinadas para finalidades de uso, assim como estabelecendo as áreas que devem ser preservadas. Deve-se enfatizar que, apesar dessa prescrição, em decorrência de pressão antrópica indiscriminada, essas áreas vêm sendo exploradas sem o cumprimento da legislação vigente.

O Código Florestal Brasileiro, Lei no ${ }^{\circ}$ 4.771/65, em seu Art. 1ํestabelece que "as florestas do território nacional e as demais formas de vegetação, reconhecidas de utilidade as terras que revestem, são bens de interesse comum a todos os habitantes do país, exercendo-se o direito de propriedade, com as limitações que a legislação em geral e especialmente essa Lei estabelecem” (BRASIL, 1965). Deve-se enfatizar que a Medida Provisória n ${ }^{\circ}$ 2.166-67, de 24 de agosto de 2001, acresce dispositivos a essa Lei e define o módulo agrário quanto ao tamanho da propriedade rural, assim como referenda as áreas de preservação permanente e estabelece a área de reserva legal nas propriedades rurais. Também, fica estabelecido que as ações que desconsiderem as disposições da Lei na sua utilização e exploração são consideradas como de uso nocivo à propriedade. No Art. $2^{2}$ da referida
Lei anteriormente citada, as nascentes perenes ou intermitentes são consideradas como áreas de preservação permanente, cuja área de vegetação ciliar em seu entorno deve conter um raio mínimo de $50 \mathrm{~m}$. Ab’Saber (2000) definiu vegetação ciliar como aquela associada aos cursos e reservatórios d’água, independentemente de sua área ou região de ocorrência, de sua composição florística e localização.

Os desequilíbrios gerados entre a utilização excessiva e a conservação dos recursos florestais parecem ter como causa principal a exploração excessiva, em que, na maioria das vezes, nem se conhecem os mecanismos de regeneração natural em tais ambientes. Nesse sentido, de acordo com Maury-Lechon (1993) não se podem preservar os remanescentes florestais quando as comunidades humanas não têm outras fontes de energia doméstica, nem há florestas comerciais que atendam às necessidades humanas e ecológicas.

Em algumas situações, em contraposição ao uso da regeneração artificial, pode-se utilizar a regeneração natural orientada, que é um método simples e de baixo custo que pode proporcionar a obtenção de florestas produtivas em áreas anteriormente degradadas (SHONO et al., 2007). Segundo esses autores, em áreas muito fragmentadas e com forte ação antropogênica causando degradação ambiental mais severa existem barreiras físicas, químicas e biológicas à regeneração natural. Nesse caso, há necessidade da intervenção do homem para iniciar os processos de recobrimento.

Para restaurar áreas degradadas nas regiões tropicais, é necessário que alguns fatores sejam observados, principalmente as condições socioeconômicas das comunidades locais, pois em algumas situações esses fatores podem ser mais críticos na determinação do método mais apropriado do que os fatores ecológicos e silviculturais (LAMB e LAWRENCE, 1993).

Para atingir tais objetivos, vários modelos podem ser empregados com essa finalidade. Segundo Kageyama e Gandara (2000), podem-se empregar plantios ao acaso, modelos sucessionais, plantios por sementes, condução da regeneração natural, modelos com espécies raras e comuns e também restauração em ilhas de vegetação. Porém, algumas atividades devem ser planejadas para obter resultados satisfatórios mais rapidamente, como: promover o isolamento das áreas, remover os fatores causadores da degradação, eliminar ou desbastar

Revista Árvore, Viçosa-MG, v.35, n.2, p.265-277, 2011 
espécies que possam atuar como competidoras, promover adensamento das áreas com mudas ou sementes das espécies selecionadas, fazer enriquecimento das áreas com as espécies mais importantes, realizar plantios mistos, induzir e conduzir propágulos autóctones, transferir propágulos alóctones e utilizar espécies atrativas para a fauna (RODRIGUES e GANDOLFI, 2000).

Considerando os aspectos mencionados e a importância das áreas de nascentes da sub-bacia hidrográfica do rio Poxim para a proteção dos recursos hídricos, tanto para o abastecimento humano quanto para fins agrícolas e pecuários, este trabalho foi realizado com os seguintes objetivos: a) realizar diagnóstico das nascentes quanto ao fluxo de água e estado de conservação e b) apresentar informações sobre a composição florística e uso dos solos para subsidiar futuros programas para a restauração da vegetação no entorno dessas e restabelecer o equilíbrio ambiental da região.

\section{MATERIAL E MÉTODOS}

\subsection{Caracterização da sub-bacia hidrográfica do rio Poxim}

A sub-bacia hidrográfica do rio Poxim encontra-se na porção Leste do Estado de Sergipe, abrangendo parte dos Municípios de Itaporanga d’Ajuda, Areia Branca, Laranjeiras, Nossa Senhora do Socorro, São Cristóvão e Aracaju. Está localizada entre as coordenadas geográficas de $10^{\circ} 55^{\prime}$ e $10^{\circ} 45^{\prime}$ de latitude Sul e $37^{\circ} 05^{\prime}$ e $37^{\circ} 22^{\prime}$ de longitude Oeste; recebe as águas dos rios Poxim-Mirim, Poxim-Açu e Pitanga (Figura 1). De formato alongado, no sentido Noroeste-Sudeste, essa unidade de planejamento possui área de 397,95 km2, sendo limitada, ao Sul, pela bacia hidrográfica do rio VazaBarris e, ao Norte, pelo rio Sergipe. As suas principais nascentes localizam-se a Oeste, limite final da Serra dos Cajueiros, e sua foz, a Leste, no complexo estuarino Sergipe/Maré do Apicum, próxima ao Oceano Atlântico (AGUIAR NETTO et al., 2007).

Essa unidade de planejamento encontra-se inserida nos domínios da Província Costeira e Margem Continental, representadas pelas bacias sedimentares costeiras mesocenozóicas e suas extensões submersas na margem continental, desenvolvidas a partir do Jurássico (SANTOS, 2003). A forma de relevo dominante na subbacia hidrográfica do rio Poxim é de colina com cristas e topos arredondados, embora também apareçam os

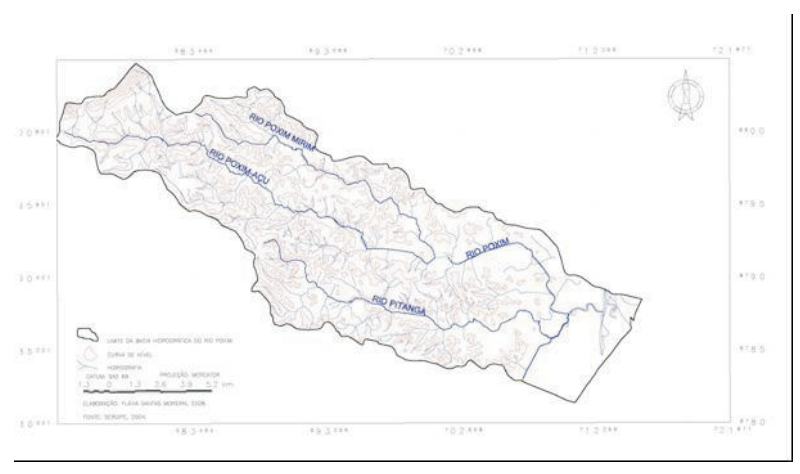

Figura 1 - Mapa base da sub-bacia hidrográfica do rio Poxim, estado de Sergipe.

Figure 1 - Base map of the Poxim river sub-basin, State of Sergipe.

interflúvios tabulares. A quase homogeneidade das formas é devido às características sedimentares das rochas, variando, todavia, o nível de aprofundamento da drenagem.

De acordo com a classificação climática de Köppen, a sub-bacia hidrográfica do rio Poxim se enquadra no tipo As (clima tropical úmido com seca no verão), em virtude da proximidade do mar e do baixo relevo, exposto aos ventos alísios. Para Soares (2001), os índices pluviométricos apresentam valores totais médios anuais bastante distintos e coerentes, sendo na faixa litorânea equivalentes a $1.900 \mathrm{~mm}$, na parte média a $1.800 \mathrm{~mm}$ e na superior a $1.600 \mathrm{~mm}$. Silva (2001) acrescentou que o período chuvoso concentra-se nos meses de março a julho. A temperatura oscila entre $23^{\circ} \mathrm{C}$ nos meses mais frios (julho e agosto) e $31{ }^{\circ} \mathrm{C}$ nos mais quentes (dezembro e janeiro).

A partir de uma base cartográfica (SERGIPE, 2004) foram obtidas informações que permitiram fazer a caracterização fisiográfica da sub-bacia hidrográfica do Poxim, de acordo com metodologia proposta por Silveira (2007), e, ainda, obtiveram-se dados para elaborar os mapas físicos e espacializar os dados de campo.

\subsection{Classificação das nascentes}

Para realizar o diagnóstico das nascentes da sub-bacia hidrográfica do rio Poxim, estas foram classificadas quanto ao tipo de reservatório e estado de conservação, com base nos trabalhos realizados por Castro (2001) e Pinto et al. (2005). Para o tipo de reservatório, as nascentes foram classificadas em: a) pontuais (quando o fluxo ocorre em apenas 
um local) e b) difusas (quando o fluxo ocorre em mais de um local). Quanto ao estado de conservação foram classificadas em: a) preservadas (quando apresentava raio mínimo de $50 \mathrm{~m}$ de vegetação em seu entorno, de acordo com o código florestal), b) perturbadas (sem 50 m de vegetação, mas em bom estado) e c) degradadas (sem o mínimo de vegetação que exerça uma função de proteção).

No diagnóstico, também foram identificados as formas de uso e ocupação do solo e o tipo fisionômico da vegetação remanescente. As nascentes foram georreferenciadas, obtendo-se as respectivas coordenadas e altitude.

\subsection{Composição florística das nascentes}

Para auxiliar na definição de propostas para a sua recuperação, a vegetação no entorno das principais nascentes e margens dos cursos d’água foi avaliada quanto à composição florística.

A relação das espécies arbóreas foi obtida por meio de coleta de material botânico (vegetativo e, ou, reprodutivo), quando presentes na época da realização do diagnóstico. As principais áreas levantadas foram situadas no povoado Cajueiro, Município de Itaporanga D’Ajuda; Fazenda Cafuz e Campus Rural da Universidade Federal de Sergipe, Município de São Cristóvão. Para essa identificação foi realizada coleta de material botânico, herborização e confecção de exsicatas. O reconhecimento dos exemplares foi realizado por comparação em literatura especializada (LORENZI, 1992, 1998) e com amostras já identificadas no Laboratório de Dendrologia e Ecologia Florestal da Universidade Federal de Sergipe, de acordo com o sistema de Cronquist (1981). A vegetação predominante, segundo a classificação de Velloso et al. (1991), corresponde à Floresta Ombrófila Semidecidual. A confirmação das espécies foi realizada por taxonomistas especialistas do Herbário MAC, do Instituto do Meio Ambiente de Alagoas (IMA - AL).

Para a classificação das espécies nos respectivos grupos ecológicos, foi adotada a classificação de Swaine-Whitmore (1988) e adaptada por Oliveira-Filho (1995), sendo consideradas três categorias: pioneiras $(\mathrm{P})$, clímax exigente em luz $(\mathrm{CL})$ e clímax tolerante à sombra (CS).

\section{RESULTADOS E DISCUSSÃO}

\subsection{Caracterização da sub-bacia hidrográfica e avaliação das nascentes quanto ao fluxo de água e estado de conservação}

A sub-bacia hidrográfica do rio Poxim apresenta-se com formato alongado, no sentido Noroeste-Sudeste, sendo um rio de planície, com fluxo d’água lento. $\mathrm{Na}$ Tabela 1, encontram-se as características fisiográficas e as categorias de classificação das nascentes dos três principais rios que compõem essa unidade de planejamento.

A partir da análise morfométrica e suas relações com o meio, pode-se prever e programar a capacidade de vazão dos corpos d'água com grande eficiência, a fim de criar planos de ação e metas de controle da

Tabela 1 - Características fisiográficas e categorias de classificação das nascentes dos principais cursos d’água do rio Poxim - Sergipe. UFS, São Cristóvão-SE, 2007.

Table 1- Physiographic characteristics and classification categories of the main watercourses springs of the Poxim river - Sergipe (SE). UFS (Universidade Federal de Sergipe), São Cristóvão, SE, 2007.

\begin{tabular}{|c|c|c|c|}
\hline \multirow[t]{2}{*}{ VARIÁVEIS } & \multicolumn{3}{|c|}{ RIOS } \\
\hline & Poxim-açu & Poxim-mirim & Pitanga \\
\hline \multicolumn{4}{|c|}{ Fisiografia } \\
\hline Área $\left(\mathrm{km}^{2}\right)$ & 135,9 & 68,17 & 106,07 \\
\hline Compacidade & 1,74 & 1,73 & 1,66 \\
\hline Ordem Strahler & $4 \underline{a}$ & $4 \underline{a}$ & $4^{\underline{a}}$ \\
\hline Comprimento (km) & 32,10 & 19,52 & 29,70 \\
\hline \multicolumn{4}{|c|}{ Nascentes } \\
\hline Fluxo de água & Intermitente & Perene & Perene \\
\hline Reservatório & Pontual & Pontual & Pontual \\
\hline Declividade (\%) & $25-100$ & $25-45$ & $25-45$ \\
\hline Categoria & Degradada & Preservada & Perturbada \\
\hline
\end{tabular}


ocupação desde as nascentes, passando pelas margens e culminando na área da foz, objetivando uma política de uso racional da sub-bacia hidrográfica do rio Poxim. Os rios Poxim-Açu, Poxim-Mirim e Pitanga apresentam-se como sub-bacias hidrográficas de pequeno tamanho e ordem de Strahler reduzida. Os valores dos coeficientes de compacidade encontrados reforçam a forma retangular dessas unidades de planejamento e indicam pequena probabilidade de enchentes, conforme descrito por Garcez e Alvarez (1988).

A nascente principal do rio Poxim-Açu é classificada como pontual, intermitente, sem raio mínimo de $50 \mathrm{~m}$ de vegetação em seu entorno, sendo considerada degradada. Como causas da degradação observadas, podem-se considerar as frequentes queimadas promovidas na área e também a retirada de madeira pelas comunidades locais, que é empregada para diversas finalidades, como uso doméstico e para consumo em casas de farinhas da região. A declividade na área da serra varia de 25 a 100\%. A nascente secundária é difusa, apresentando dois pontos de fluxo. Em ambos os casos, essas foram consideradas degradadas, em função da supressão quase total da vegetação no entorno, restando apenas pequenas faixas de vegetação descontínuas.

Considerando a classificação das nascentes, verificou-se que a distinção pelos moradores entre a nascente principal do rio Poxim-Açu, situada na Serra do Cajueiro e atualmente com fluxo de água somente no período chuvoso, e a nascente secundária, com fluxo de água no período seco, nos meses de outubro a janeiro, torna o rio com característica peculiar de intermitente. Tal fato pode estar relacionado à ausência da vegetação, em decorrência dos desmatamentos e queimadas contínuas realizadas pelas comunidades locais.

Observou-se que a nascente principal do rio PoximMirim apresentava bom estado de preservação, com vegetação no seu entorno em raio mínimo de $50 \mathrm{~m}$. A nascente foi classificada como pontual e perene. O fragmento no entorno da nascente mostrava-se com sua vegetação com composição florística e fitofisionomia característica da região. Outro fator observado foi a declividade do terreno na área de entorno da nascente, variando de 25 a $45 \%$.

O rio Pitanga apresenta nascente principal localizada em área de mata fechada e com relevo fortemente inclinado. A nascente é pontual, perene e perturbada (presença de vegetação sem raio mínimo de 50 m em seu entorno). Ao longo do trecho do rio existem vários minantes nas regiões mais altas. À semelhança do rio Poxim-Mirim, a declividade da área também variou de 25 a $45 \%$.

Considerando o perfil das 20 nascentes diagnosticadas na sub-bacia hidrográfica do rio Poxim (Tabela 2), nos três cursos d'água verificou-se variação na altitude de 7 a 281. Todavia, em relação à sua estrutura, pode-se dizer que se trata de área com topografia plana. Quanto ao fluxo de água, 15 nascentes, que correspondem a $75 \%$, apresentavam fluxo pontual e cinco (25\%), fluxo difuso.

Em relação ao estado de conservação, observou-se que somente duas (10\%) poderiam ser consideradas preservadas, ou seja, apresentavam o raio mínimo de vegetação de $50 \mathrm{~m}$ no seu entorno, conforme prescrito no Código Florestal (Lei 4.771/65). Entretanto, em 18 nascentes (90\%) observou-se significativa ação antrópica. Na categoria perturbada, diagnosticaram-se cinco nascentes, que correspondem a $25 \%$; e na maior proporção 13 nascentes, ou seja, 65\%, encontravam-se em avançado estádio de antropização, sendo, assim, classificadas como degradadas.

Os principais problemas observados em relação à situação das nascentes estavam associados ao modo de uso e ocupação dos solos. Nesse aspecto, fator determinante para o elevado percentual de nascentes sob condição de pressão de antropização é decorrente do tamanho da propriedade, uma vez que nessa região ocorre predominância de pequenas propriedades rurais, com base na agricultura familiar, cujo tamanho varia de 1 a 10 ha. Essas propriedades, na maioria das vezes, exploram as áreas de nascentes com finalidade de produção agrícola para subsistência familiar.

A presença de grande número de pequenas propriedades rurais na sub-bacia hidrográfica do rio Poxim, por analogia ao mencionado por Lamb et al. (2005), constitui um mosaico de usos da terra, que inclui os fragmentos ainda remanescentes, áreas de produção agrícola e áreas degradadas, principalmente nas nascentes. De acordo esses autores, raramente é possível reflorestar áreas tão complexas, especialmente se estão ocupadas por muitas pequenas propriedades. Nessas condições, em geral a restauração é feita considerando-se os sítios particulares, como: áreas ciliares, zonas-tampão no entorno das florestas remanescentes, corredores 
Tabela 2 - Classificação das nascentes da sub-bacia hidrográfica do rio Poxim, Estado de Sergipe-SE, quanto ao tipo de reservatório e estado de conservação. Pt - pontual; Di - difusa; Pr - preservada; Pe - perturbada; Dr - degradada. UFS, São Cristóvão-SE, 2007.

Table 2 - Watershed springs classification of the Poxim river, State of Sergipe - SE, the type of reservoir and conservation status. Pt - punctual, Di - diffuse, Pr - preserved, Di - disturbed, Dr - degraded. UFS, São Cristóvão, SE, 2007.

\begin{tabular}{|c|c|c|c|c|c|c|c|c|}
\hline \multirow[t]{2}{*}{ № } & \multirow[t]{2}{*}{ Latitude } & \multirow[t]{2}{*}{ Longitude } & \multirow[t]{2}{*}{ Alt. (m) } & \multicolumn{2}{|c|}{ Reservatório } & \multicolumn{3}{|c|}{ Conservação } \\
\hline & & & & $\mathrm{Pt}$ & $\mathrm{Di}$ & $\mathrm{Pr}$ & $\mathrm{Pe}$ & $\mathrm{Dr}$ \\
\hline 01 & 0675991 & 8802446 & 188 & $\mathrm{X}$ & - & - & - & $\mathrm{X}$ \\
\hline 02 & 0675479 & 8802676 & 238 & $X$ & - & - & - & $X$ \\
\hline 03 & 0675392 & 8802664 & 270 & $\mathrm{X}$ & - & - & - & $\mathrm{X}$ \\
\hline 04 & 0675303 & 8802618 & 281 & $\mathrm{X}$ & - & - & - & $\mathrm{X}$ \\
\hline 05 & 0675133 & 8800040 & 161 & - & $X$ & - & - & $\mathrm{X}$ \\
\hline 06 & 0674499 & 8801088 & 178 & $\mathrm{X}$ & - & - & - & $\mathrm{X}$ \\
\hline 07 & 0677383 & 8802310 & 179 & - & $\mathrm{X}$ & - & $\mathrm{X}$ & - \\
\hline 08 & 0684456 & 8802262 & 111 & $\mathrm{X}$ & - & $\mathrm{X}$ & - & - \\
\hline 09 & 0684535 & 8802188 & 107 & $X$ & - & $\mathrm{X}$ & - & - \\
\hline 10 & 0688567 & 8792632 & 103 & $\mathrm{X}$ & - & - & $X$ & - \\
\hline 11 & 0688566 & 8792636 & 134 & $X$ & - & - & $X$ & - \\
\hline 12 & 0693488 & 8792888 & 54 & $X$ & - & - & - & $X$ \\
\hline 13 & 0705665 & 8790622 & 7 & - & $X$ & - & - & $X$ \\
\hline 14 & 0690802 & 8798882 & 68 & $X$ & - & - & - & $X$ \\
\hline 15 & 0689552 & 8798156 & 74 & $X$ & - & - & - & $X$ \\
\hline 16 & 0698538 & 8794926 & 36 & - & $X$ & - & $X$ & - \\
\hline 17 & 0698745 & 8793560 & 20 & $X$ & - & - & - & $X$ \\
\hline 18 & 0681310 & 8800556 & 96 & - & $X$ & - & - & $X$ \\
\hline 19 & 0681499 & 8799596 & 115 & $X$ & - & - & $\mathrm{X}$ & - \\
\hline \multirow[t]{2}{*}{20} & 0681094 & 8798808 & 124 & $\mathrm{X}$ & - & - & - & $\mathrm{X}$ \\
\hline & & & Total & 15 & 5 & 2 & 5 & 13 \\
\hline
\end{tabular}

ecológicos, áreas com processo de erosão e as encostas, entre outras. Entretanto, no mosaico da paisagem a efetiva conservação da biodiversidade e restauração das funções ecológicas só podem ser bem-sucedidas considerando-se tais sítios (LAMB et al., 2005).

Com base nas informações, é possível e necessário discutir formas de se aplicar a Legislação para recompor as nascentes, sem gerar quadro de degradação social. Entre as principais formas de usos do solo, nas pequenas propriedades com agricultura familiar destacam-se agricultura e pastagens (Tabela 3 ).

Entre as 20 nascentes diagnosticadas, observaram-se atividades agrícolas em 10 delas, ou seja, 50\%. As pastagens estavam presentes em sete nascentes, que correspondem a 35\%. Os outros usos detectados foram, respectivamente, uma para uso como área de lavagem de roupa pelas comunidades e uma situada em área urbana. As principais culturas produzidas nas propriedades eram: mandioca (Manihot esculenta Crantz.), feijão-de-corda (Pasheolus vulgaris L.), laranja (Citrus sp.), coco (Cocos nucifera L.) e cana-de-açúcar (Saccharum officinarum L.).
Como forma predominante da vegetação característica da região onde as nascentes estão situadas, observou-se que a fisionomia arbórea estava presente em 17 delas (85\%). Nas outras três, não foi possível indicar a forma característica da vegetação, em face do estado atual da área. Entre as nascentes com vegetação, ainda se observou que em 3 (15\%) delas foram constatadas queimadas no período do diagnóstico e 3 (15\%) apresentavam vegetação em estádio inicial de regeneração natural sem, contudo, recobrir a área de $50 \mathrm{~m}$ de raio, prescrito na Lei.

A partir do diagnóstico realizado, devem ser propostas medidas imediatas para se reverter o atual quadro de degradação ambiental observado nas nascentes da sub-bacia hidrográfica do rio Poxim. Assim, a implementação de modelos de restauração da paisagem, de gestão dos usos e ocupação do solo, sem comprometer os recursos hídricos, a biodiversidade local e regional e a própria condição das comunidades, deve levar em consideração as recomendações de Lamb et al. (2005), quanto à participação de instituições federais, estaduais e municipais; seleção adequada das espécies florestais;

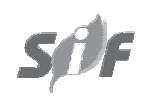

Revista Árvore, Viçosa-MG, v.35, n.2, p.265-277, 2011 
Tabela 3 - Formas de ocupação e uso dos solos no entorno de nascentes e vegetação remanescente, na sub-bacia hidrográfica do rio Poxim, Estado de Sergipe. UFS, São Cristóvão-SE, 2007.

Table 3 - Occupation forms and land use around the springs and the remaining vegetation in the watershed of the Poxim river, State of Sergipe. UFS, São Cristóvão, SE, 2007.

\begin{tabular}{|c|c|c|c|c|c|c|}
\hline \multicolumn{3}{|c|}{ Coordenadas } & \multicolumn{4}{|c|}{ Forma de uso do solo } \\
\hline № & Latitude & Longitude & Pastagem & Agricultura & Vegetação & Outros \\
\hline 1 & 0675991 & 8802446 & $\mathrm{X}$ & $\mathrm{X}$ & arbórea & \\
\hline 2 & 0675479 & 8802676 & & & arbórea (queimada) & \\
\hline 3 & 0675392 & 8802664 & & & arbórea (queimada) & \\
\hline 4 & 0675303 & 8802618 & & & arbórea (queimada) & \\
\hline 5 & 0675133 & 8800040 & & $\mathrm{X}$ & arbórea & $X$ \\
\hline 6 & 0674499 & 8801088 & & $\mathrm{X}$ & arbórea & \\
\hline 7 & 0677383 & 8802310 & & & arbórea & \\
\hline 8 & 0684456 & 8802262 & & $\mathrm{X}$ & arbórea & \\
\hline 9 & 0684535 & 8802188 & & $X$ & arbórea & \\
\hline 10 & 0688567 & 8792632 & & $\mathrm{X}$ & arbórea (regeneração) & \\
\hline 11 & 0688566 & 8792636 & & $X$ & arbórea & \\
\hline 12 & 0693488 & 8792888 & $\mathrm{X}$ & & arbórea & \\
\hline 13 & 0705665 & 8790622 & & & sem vegetação & $\mathrm{X}$ \\
\hline 14 & 0690802 & 8798882 & & $\mathrm{X}$ & sem vegetação & \\
\hline 15 & 0689552 & 8798156 & $\mathrm{X}$ & & arbórea & \\
\hline 16 & 0698538 & 8794926 & & & arbórea & \\
\hline 17 & 0698745 & 8793560 & $\mathrm{X}$ & & arbórea & \\
\hline 18 & 0681310 & 8800556 & $\mathrm{X}$ & & sem vegetação & \\
\hline 19 & 0681499 & 8799596 & $\mathrm{X}$ & $\mathrm{X}$ & arbórea (regeneração) & \\
\hline \multirow[t]{2}{*}{20} & 0681094 & 8798808 & $\mathrm{X}$ & $\mathrm{X}$ & arbórea (regeneração) & \\
\hline & & Total & 7 & 10 & 17 & 2 \\
\hline
\end{tabular}

assistência técnica para os produtores rurais; e uso de sistemas silviculturais mais eficientes e mais rápidos e geração de bens e serviços diretos e, ou, indiretos das florestas, como pressupostos para a conservação da biodiversidade. Ainda, na escolha dos métodos ou modelos mais apropriados para a recuperação ou restauração das nascentes, devem-se levar em consideração, além dos fatores ambientais, as condições socioeconômicas das próprias comunidades, como sugerido por Lamb e Lawrence (1993) e Ketller (2001). De acordo com Santos et al. (2007), tais fatores podem interferir no grau de organização e união dos proprietários de terras e moradores, considerando a sustentabilidade dos recursos naturais, em se tratando de definir práticas para o manejo de bacias hidrográficas.

Nesse sentido, os métodos recomendados tanto com plantios convencionais, por meio de semeadura direta ou plantio de mudas (LAMB e GILMOUR, 2003), quanto se empregando a regeneração natural orientada (SHONO et al., 2007), devem ser eficientes do ponto de vista da restauração das funções ecológicas para a conservação da biodiversidade e promoção de oportunidades de se obterem retornos econômicos indiretos de tais bens. Isso pode ser alcançado com o aumento da quantidade e qualidade da água produzida na sub-bacia hidrográfica, venda de créditos de carbono, obtenção de frutos e sementes de espécies florestais para comercialização, frutíferas silvestres e plantas medicinais, entre outros, sem promover a supressão da nova vegetação estabelecida e sem modificar a sua fisionomia.

\subsection{Composição florística das áreas no entorno das nascentes}

Foram identificadas na sub-bacia hidrográfica do rio Poxim 43 espécies arbóreas, distribuídas em 26 famílias botânicas, e nas Leguminosae havia representantes das três subfamílias (Caesalpinioideae, Mimosoideae e Papilionoideae). As principais famílias presentes nos remanescentes do entorno das nascentes e ao longo dos cursos d’água eram: Leguminosae com sete espécies, distribuídas em seis gêneros; e Anacardiaceae, Lecythidaceae e Myrtaceae, com três espécies cada e distribuídas em três gêneros. As demais famílias contribuíram com duas espécies ou uma espécie, respectivamente (Tabela 4 ). 
Tabela 4 - Listagem florística das espécies arbóreas em áreas de nascentes da sub-bacia hidrográfica do rio Poxim, Estado de Sergipe. As espécies estão dispostas em ordem de famílias botânicas, nomes populares e grupo ecológico (GE): pioneira (P), clímax exigente em luz (CL), clímax tolerante à sombra (CS), baseado na classificação de Oliveira Filho et al. (1995), Vilela et al. (1997), Carvalho et al. (1999) e Lorenzi (1992, 1998). * sem classificação ecológica.

Table 4 - Floristic list of the tree species in springs areas in the Poxim river watershed, State of Sergipe. The species are arranged by the plant families order, common names, and ecological group (EG): "pioneer $(P)$, light demanding climax (LC), shade-tolerant climax (SC)", based on the classification by Oliveira Filho et al. (1995), Vilela et al. (1997), Carvalho et al. (1999), and Lorenzi (1992, 1998). *No ecological classification.

\begin{tabular}{|c|c|c|}
\hline Família/Espécie & Nome vulgar & G.E. \\
\hline \multicolumn{3}{|l|}{$\begin{array}{l}\text { Anacardiaceae } \\
\end{array}$} \\
\hline Anacardium occidentale L. & Cajueiro & CL \\
\hline Mangifera indica $\mathrm{L}$. & Mangueira & \\
\hline Tapirira guianensis Aubl. & Pau-pombo & $\mathrm{P}$ \\
\hline \multicolumn{3}{|l|}{ Annonaceae } \\
\hline $\begin{array}{l}\text { Xilopia brasiliensis Spreng. } \\
\text { Apocynaceae }\end{array}$ & Аросупасеае & CS \\
\hline $\begin{array}{l}\text { Hancornia speciosa Gómez } \\
\text { Araliaceae }\end{array}$ & Mangabeira & $*$ \\
\hline $\begin{array}{l}\text { Scheflera morototonii (Aubl.) Dcne. } \\
\text { Burseraceae }\end{array}$ & Pé-de-galinha & $\mathrm{P}$ \\
\hline $\begin{array}{l}\text { Protium heptaphyllum (Aubl.) Marchand } \\
\text { Cecropiaceae }\end{array}$ & Amescla & CL \\
\hline $\begin{array}{l}\text { Cecropia pachystachya Trec } \\
\text { Clusiaceae }\end{array}$ & Embaúba & $\mathrm{P}$ \\
\hline $\begin{array}{l}\text { Simphonia globulifera L.f. } \\
\text { Dilleniaceae }\end{array}$ & Ganahador/bulandi & * \\
\hline $\begin{array}{l}\text { Curatela americana L. } \\
\text { Euphorbiaceae }\end{array}$ & Lixeira & CL \\
\hline $\begin{array}{l}\text { Richeria grandis Vahl. } \\
\text { Flacourtiaceae }\end{array}$ & Jaqueira-brava & * \\
\hline $\begin{array}{l}\text { Casearia sylvestris Schwartz. } \\
\text { Lecythidaceae }\end{array}$ & Camarão & CL \\
\hline Escheweilera ovata (Cambess) Miers & Biriba & CL \\
\hline Lecythis lurida (Miers) S.A. Mori & Sapucarana & $*$ \\
\hline Gustavia augusta L. & Sapucaia & $*$ \\
\hline \multicolumn{3}{|l|}{ Leguminosae Caesalpinioideae } \\
\hline Cassia grandis L.f. & Canafístula & CL \\
\hline \multicolumn{3}{|l|}{ Leguminosae Mimosoideae } \\
\hline Stryphonodendron pulcherrimum (Willd.) Hochr. & Maria-farinha/timbó & CL \\
\hline Inga laurina Willd. & Ingá & CL \\
\hline Inga uruguensis Hooker \& Arnott & Ingá & CL \\
\hline $\begin{array}{l}\text { Samanea tubulosa (Benth) Barney \& Grimes } \\
\text { Leguminosae Papilionoideae }\end{array}$ & Bordão-de-velho & $\mathrm{P}$ \\
\hline Andira fraxinifolia Benth. & Angelim & CS \\
\hline Machaerium aculeatum Raddi & Mau-vizinho & $\mathrm{P}$ \\
\hline \multicolumn{2}{|l|}{ Malpighiaceae } & $\mathrm{P}$ \\
\hline \multicolumn{3}{|l|}{ Melastomataceae } \\
\hline Miconia ligustroides Nouden & Erva-de-rato & CL \\
\hline Tibouchina mutabilis Cong. & Flor-de-natal & CL \\
\hline \multicolumn{3}{|l|}{ Meliaceae } \\
\hline Guarea guidonea (L.) Sleumer & Jitó & CS \\
\hline
\end{tabular}


Tabela 4 - Cont.

Table 4-Cont.

Moracea $-\frac{\text { Cont. }}{-}-----------$

Ficus sp.

Brosimum cf. guianense (Aubl.)

Gameleiro branco CS

Myrtaceae

Campomanesia xantocharpa O. Berg.

Eugenia sp.

Psidium sp.

Nyctaginaceae

Guapira sp.

Conduru CI

Palmae

Cocos nucifera $\mathrm{L}$.

Piperaceae

Piper arboreum Aubl.

Rhamnaceae

Zizyphus joazeiro Mart.

Guabiraba

Murta

Araçá

CS

João-mole

CS

Rubiaceae

Genipa americana L.

Coqueiro

CS

Faramea sp.

Pipeira

Sapindaceae

Cupania revoluta Radlk

$\begin{array}{ll}\text { Pipeira } & * \\ \text { Juazeiro } & \text { CL }\end{array}$

Allophyllus edulis (St. Hil.) Radlk.

Jenipapo

CS

Simaroubaceae

Simarouba amara Aubl.

Camboatá CL

Estralador CS

Sterculiaceae (Malvaceae)

Guazuma ulmifolia Lam.

Paraíba

CL

Verbenaceae

Vitex polygama Cham.

Mutamba

Com base nessas informações, espera-se indicar mais facilmente as espécies que apresentam potencial para fins de restauração das nascentes e, ou, cursos d’água da sub-bacia hidrográfica do rio Poxim, promovendo recobrimento mais rápido e mais eficiente em termos de resgate e conservação das biodiversidades local e regional. E, ainda, essas espécies apresentam, também, vantagens sociais e econômicas para as comunidades rurais dessas áreas, seja por alguns bens e serviços ecológicos, seja por benefícios diretos, sem que haja supressão da vegetação ou retirada de madeira em tais áreas.

De acordo com Souza e Siqueira (2001), há registros de 469 espécies da Mata Atlântica de Sergipe, sendo 38\% de espécies arbóreas, distribuídas em 94 famílias. Entre elas, as com maior número de representantes são Myrtaceae, Leguminosae e Rubiaceae, apresentando 51, 47 e 36 espécies, respectivamente.

Para a escolha e sugestão de modelos de restauração ecológica que podem ser empregados na sub-bacia hidrográfica do rio Poxim, o primeiro passo é selecionar adequadamente as espécies que podem ser utilizadas com essa finalidade. Segundo Rodrigues e Gandolfi (2000), a seleção adequada representa a principal ou uma das principais garantias de sucesso da restauração.

O plantio das espécies selecionadas deve ser entendido como o primeiro passo para acelerar a restauração nas áreas onde se observa baixa resiliência, uma vez que esse fato impossibilita o uso da própria regeneraçao natural. No entanto, entende-se que ao longo do desenvolvimento da floresta vários fatores podem interferir na sucessão florestal. De acordo com Rodrigues e Gandolfi (2000), a sucessão florestal deve ser entendida não apenas como simples substituição gradativa de espécies ao longo do tempo e, sim, como substituição de grupos ecológicos ou de categorias funcionais.

Simplesmente, portanto, plantar mudas de espécies florestais que correspondem a uma diversidade regional ou local não necessariamente assegura a restauração dos ambientes degradados, como mencionado também por Rodrigues e Gandolfi (2000). Nesse caso, é necessário que os fatores de degradação sejam retirados da área e que se faça o monitoramento da área em processo

Revista Árvore, Viçosa-MG, v.35, n.2, p.265-277, 2011 
de restauração, assegurando que assim se obterão resultados de acordo com os objetivos propostos, como mencionado por Lamb et al. (2005).

Levando em consideração o estado de conservação das áreas de nascentes da sub-bacia hidrográfica do rio Poxim e a composição florística ainda remanescente na área, com a presença dos grupos ecológicos de acordo com a classificação de Swaine e Whitmore (1988), é possível sugerir diferentes modelos para restauração daquelas perturbadas e degradadas.

Em se tratando das nascentes perturbadas, uma das primeiras preocupações está relacionada à necessidade de se fazer o isolamento das áreas e retirar os fatores que causam impactos negativos à sua regeneração natural. Como mencionado por Rodrigues e Gandolfi (2000), nessas áreas podem-se monitorar os propágulos das espécies autóctones ou, ainda, para acelerar a restauração, transferir sementes e plântulas de espécies alóctones. Diante da presença de espécies da flora regional de interesse na área, pode-se também fazer o enriquecimento das áreas com as espécies de maior importância, como proposto por Kageyama e Gandara (2000).

Nas áreas de nascentes degradadas, para se ter efetivo processo de restauração é necessário que se façam intervenções para orientar a regeneração artificial. Entre os modelos mais comumente utilizados no Brasil com essa finalidade, encontram-se os plantios mistos, por meio de mudas, mais comumente empregado (DAVIDE et al., 2000), e a utilização da semeadura direta, como mencionado por Ferreira et al. (2007) e Ferreira et al. (2009), tomando-se como base o uso das próprias espécies presentes nas áreas estudadas, como também recomendadas por Kageyama e Gandara (2000).

É necessário enfatizar que a restauração senso strictu é uma meta quase inatingível, pois haveria a necessidade de devolver o ecossistema à sua condição original ou trajetória história, como definido por Rodrigues e Gandolfi (2001). Nesse caso, segundo esses autores, entende-se como a necessidade de restaurar o ambiente o mais próximo possível da sua condição anterior à degradação, ou seja, restauração senso lato, que é definida como estado estável alternativo ou intermediário.

Apesar de em algumas situações se recomendarem modelos produtivos com a finalidade de restauração ambiental, a exemplo dos sistemas agroflorestais, como mencionado por Rodrigues e Gandolfi (2000), nesas situações das nascentes da sub-bacia hidrográfica do rio Poxim não seriam recomendados, por não se encontrar aparato legal na Lei 4.771/65 e por serem as nascentes classificadas como áreas de preservação permanentes. Nesse sentido, a sua função está designada como ecológica de proteção.

\section{CONCLUSÕES}

Das 20 principais nascentes que compõem a subbacia hidrográfica do rio Poxim, composta pelos rios Poxim-Mirim, Poxim-Açu e Pitanga, 90\% apresentaram significativa antropização, a maioria delas (65\%) com elevada degradação (sem raio mínimo de 50 m de vegetação em seu entorno) e ocupada por agricultura (50\%) e pastagem (35\%). Somente duas nascentes foram classificadas como preservadas e apresentavam raio mínimo de 50 m de vegetação em seu entorno.

Quanto à composição florística, foram identificadas 43 espécies arbóreas que apresentavam potencial para serem utilizadas em projetos futuros para restauração das nascentes e dos cursos d'água nessa sub-bacia hidrográfica, podendo-se empregá-las em diferentes modelos com tal finalidade.

\section{AGRADECIMENTOS}

À Companhia de Saneamento do Estado de Sergipe - DESO, Superintendência de Recursos Hídricos, pelo suporte financeiro; à Promotoria Pública do Estado de Sergipe, pelo apoio; ao Sr. Antônio de Jesus Rosa, pelo trabalho de campo; e à Rosângela Pereira Lyra Lemos e toda a sua equipe, pela identificação das espécies no Herbário MAC, do Instituto do Meio Ambiente de Alagoas (IMA - AL).

\section{REFERÊNCIAS}

AB'SABER, A. N. O suporte geoecológico das florestas beiradeiras (ciliares). In: RODRIGUES, R. R.; LEITÃO FILHO, H. F. (Eds.) Matas ciliares: conservação e recuperação. São Paulo: EDUSP/FAPESP, 2000. p.15-25.

AGUiAR NETTO, A. O. et al. Cenário dos corpos d’água na sub-bacia hidrográfica do rio Poxim - Sergipe, na zona urbana, e suas relações ambientais e antrópicas. In: SIMPÓSIO BRASILEIRO DE RECURSOS HÍDRICOS, 17. 2007, São Paulo. Simpósio... São Paulo: 2007. p.1-19.

Revista Árvore, Viçosa-MG, v.35, n.2, p.265-277, 2011 
BRASIL. Lei no 4771, de 15 de setembro de 1965. Institui o novo código florestal brasileiro. Diário Oficial da República Federativa do Brasil. Poder Executivo, Brasília: 1965.

CASTRO, P. S. Recuperação e conservação de nascentes. CPT, 2001. 84p. (Série

Saneamento e Meio Ambiente, n.26).

CARVALHO, D. A. et al. Estudos florísticos e fitossociológicos em remanescentes de florestas ripárias do Alto São Francisco e Bacia do Rio Doce - MG. Lavras: UFLA, 1999. 39p.

CLEWELL, A.; ARONSON, J.; WINTERHALDER, K. Fundamentos de restauração ecológica. Tucson: Society for Ecological Restoration International Science \& Policy Working Group. 2004. 18p. (www.ser.org - http:// www.efraim.com.br/

SER_Primer3_em_portugues.pdf. Acesso em: 17 de Dezembro de 2009).

CRONQUIST, A. An integrated system of classification of flowering plants. New York: Columbia University, 1981. 555p.

DAVIDE, A. C. et al. Restauração de matas ciliares. Informe Agropecuário, v.21, n.207, p.65-74, 2000.

FELFILI, J. M.; REZENDE, R. P. Comunicações - Técnicas Florestais: conceitos e métodos em fitossociologia.. Brasília: UNB, 2003. 68p.

FERREIRA, R. A. et al. Semeadura direta com espécies arbóreas para recuperação de ecossistemas florestais. Cerne, v.13, n.3, p.21-279, 2007.

FERREIRA, R. A. et al. . Semeadura direta com espécies florestais na implantação de mata ciliar no Baixo São Francisco em Sergipe. Scientia Forestalis, v.37, n.81, p.37-46, 2009.

GARCEZ, L. N.; AlVAREZ, G. A. Hidrologia. 2.ed. São Paulo: Edgard Blücher, 1988. 291p.

KAGEYAMA, P.; GANDARA, F. Recuperação de áreas ciliares. RODRIGUES, R. R.; LEITÃO FILHO, H. F. (Eds.) Matas ciliares: conservação e recuperação. São Paulo: EDUSP/ FAPESP, 2000. p.249-269.

Revista Árvore, Viçosa-MG, v.35, n.2, p.265-277, 2011
KETTLER, J. S. A dependence on people: examples of ecological restoration and land-based economies from three countries. Ecological Restoration, v.19, n.1, p.27-33, 2001.

LAMB, D.; ERSKINE, P. D.; PARROTA, J. A. Restoration of degraded tropical rain forest landscapes. Science, v.310, p.1628-1632, 2005.

LAMB, D.; GILMOUR, D. Rehabilitation and restoration of degraded forests. Issues in Forest Conservation, IUCN, 2003.110p.

LAMB, D.; LAWRENCE, P. Mixed plantations using high value rainforest trees in Australia. In: LIETH, H.; HOLMANN, M. (Eds.) Restoration of tropical forest ecosystems. Netherlands: Kluver Academic Publishers, 1993. p.101-108.

LORENZI, H. Árvores brasileiras: manual de identificação e cultivo de plantas nativas arbóreas do Brasil. Nova Odessa: Plantarum, 1992. 352p.

LORENZI, H. Árvores brasileiras: manual de identificação e cultivo de plantas nativas arbóreas do Brasil. 2a edição. Nova Odessa: Plantarum, 1998. 352p.

MAURY-LECHON, G. Biological and plasticity of juvenile trees stages to restorate degraded tropical forests. In: LIETH, H.; HOLMANN, M. (Eds.) Restoration of tropical forest ecosystems. Netherlands: Kluver Academic Publishers, 1993. p.37-46.

MILLER, J. R.; HOBBS, R. J. Habitat restoration do we know what we're doing? Restoration Ecology, v.15, n.3, p.382-390, 2007.

OLIVEIRA-FILHO, A. T. et al. Estudos florísticos e fitossociológicos em remanescentes de matas ciliares do alto médio Rio Grande. Belo Horizonte: CEMIG, 1995. 27p.

PINTO, L. V. A. et al. Estudo da vegetação como subsídios para propostas de recuperação das nascentes da bacia hidrográfica do Ribeirão Santa Cruz, Lavras, MG. Revista Árvore, v.29, n.5, p.775-739, 2005.

PNUMA/MMA. Geo Brasil - perspectives do meio ambiente no Brasil. Brasília: MMA/IBAMA, 2002. 132p. 
RODRIGUES, R. R.; GANDOLFI, S. Conceitos, tendências e ações para a recuperação de florestas ciliares. In: RODRIGUES, R. R.; LEITÃO FILHO, H. F. (Eds.) Matas ciliares: conservação e recuperação. São Paulo: EDUSP/ FAPESP, 2000. p.235-247.

SANTOS, G. V. et al. Análise hidrológica e socioambiental da bacia hidrográfica do Córrego do Romão dos Reis - Viçosa, MG. Revista Árvore, v.31, n.5, p.931-940, 2007.

SANTOS, M. S. Estudo da sub-bacia do rio Poxim/SE: uma proposta arqueológica. 2003. 75f. 2003. 75p. Dissertação (Mestrado em Geografia) - UFS/ Geografia, São Cristóvão, 2003.

SANTOS, A. L. C. Diagnóstico dos fragmentos de Mata Atlântica do estado de Sergipe através de sensoriamento remoto. 2009. 74f. Dissertação (Mestrado em Desenvolvimento e Meio Ambiente) -: UFS/PRODEMA, São Cristóvão, 2009.

SERGIPE (Estado). Secretaria de Estado do Planejamento, da Ciência e da Tecnologia. Atlas digital sobre recursos hídricos Sergipe. SEPLANTEC/SRH. Sergipe, 2004. CD-ROM.

SHONO, K.; CADAWENG, E. A.; DURST, P. B. Application of assisted natural regeneration to restore degraded tropical forestlands. Restoration Ecology, v.15, n.4, p.620-626, 2007.
SILVA, Z. F. B. Cenário atual da secção urbana do Rio Poxim. São Cristóvão: UFS/ Gestão de Recursos Hídricos em Meio Ambiente, 2001. 85 p. (Monografia de Especialização).

SILVEIRA, A. L. L. Ciclo hidrológico e bacia hidrográfica. In: TUCCI, C. E. M. (Org.). Hidrologia: ciência e aplicação. 4.ed. Porto Alegre: EDUFRGS, 2007. p.35-51.

SOARES, J. A. O Rio Poxim, processo urbano e meio ambiente. São Cristóvão: UFS/Gestão de Recursos Hídricos em Meio Ambiente, 2001. 67p. (Monografia de Especialização).

SOUZA, M. F. L.; SIQUEIRA, E. R. Caracterização florística e ecológica da Mata Atlântica de Sergipe. In: SIQUEIRA. E. R.; RIBEIRO, F. E. Mata Atlântica de Sergipe. Aracaju: EMBRAPA/CPACT, 2002. p.9-49.

SWAINE, M. D.; WHITMORE, T. C. On the definitions of ecological species groups in tropical forest. Vegetatio, v.75, n.2, p.81-86, 1988.

VELLOSO, H. P.; RANGEL-FILHO, A. L. R.; LIMA, J. C. A. Classificação da vegetação brasileira adaptada a um sistema universal. Rio de Janeiro: IBGE, 1991. 123p.

VILELA, E. A. et al. Estudos florísticos e fitossociológicos em remanescentes de florestas ripárias do Baixo Rio Paranaíba e Alto Rio São Francisco MG. Belo Horizonte: CEMIG, 1997. 23p. 
